\title{
Peer Support at Schools: The Buddy Approach as a Prevention and Intervention Strategy for School Bullying
}

Calli Tzani-Pepelasi ${ }^{1}$, Dr. Maria Ioannou, Dr. John Synnott \& Dean McDonnell

\begin{abstract}
Previous research has shown that peer support could positively impact children's school experience and well-being and could function as school-bullying intervention and prevention. This qualitative study aimed to highlight the 'Buddy Approach' and provide insight into the positive impact it can have on both the young mentors and the mentees. A total of twenty-nine participants, divided between student mentees $(n=19)$, and student mentors $(n=10)$ took part in a series of semi-structured interviews, where open-ended questions related to the efficacy of the 'Buddy Approach'. Based on the finding, the buddy approach is valued by both mentees and mentors and is pivotal in supporting students in promoting a sense of friendship, safety, belonging, and protection, while also building a sense of responsibility, satisfaction, and pride. The buddy approach could potentially be used as an early prevention and intervention strategy for school bullying. Limitations and implications are discussed in detail.
\end{abstract}

\footnotetext{
${ }^{1}$ Corresponding author at: Department of Psychology, Human and Health Sciences, University of Huddersfield, Queensgate, Huddersfield, HD1 3DH, UK

Tel: +0044 07450266298. Email address: Kalliopi.Tzani-Pepelasis@hud.ac.uk
} 


\section{Introduction}

The holistic educational experience has been well documented to improve through the provision of additional school supports (Chong, Huan, Yeo \& Ang, 2006; Virtanen, Lerkkanen, Poikkeus \& Kuorelahti, 2014; Visser 2004). Considered an umbrella term, Peer Support (PS) is one way in which educational institutions are supporting and encouraging students to support each other, through a formalised framework (Houlston, Smith, \& Jessel, 2009). While, numerous studies highlight the benefits of PS programmes and their potential to assist in a wide variety of academic areas, such as language learning (Carhill-Poza, 2017) or literacy and numeracy (Galloway \& Burns, 2015; Henry, Castek \& O’Byrne, 2012), a growing body of research is showing that the role of PS programmes can greatly extend beyond academic outcomes and into positive psychological growth. Also, Cowie (2011) informed that peer support has also been of value, when it comes to bullying intervention; the adoption of peer support within schools can create opportunities for children and young people to be proactive in challenging bullying when they observe it. Peer supporters can play a part in this process by monitoring social interaction during break-times to support victims by reporting abusive behaviour. However, it was shown (Thornberg \& Jungert, 2013) that bystanders' behaviour has an impact on bullying behaviour. As for cyber-bullying, peer supporters can also contribute to standing against negative behaviour, whether offline or online.

Having become more popular in primary and post-primary schools across Ireland and 
the UK, the estimated PS program implementation in schools, was between $62 \%$ and $68 \%$ in 2007, and is now believed to be far more prevalent (Channon, Marsh, Jenkins \& Robling, 2013; Houlston, Smith \& Jessel, 2009). Of the numerous programmes that are in existence, such as 'Big Brothers Big Sisters' in Ireland (see Dolan, Brady, O’Regan, Russel, Canavan \& Forkan, 2010), many often use terminology, such as 'befriending', or 'mentoring', or having a 'peer buddy', the fundamental premise is to nurture a positive educational or working climate that promotes the social and emotional well-being of its members (Brady, Dolan \& Canavan, 2014).

\section{Literature Review}

Of the studies evaluating PS, an overwhelming proportion report a range of findings including increased levels of interactions with peers, increased academic engagement, improved progress on individualised social goals, increased social participation in class, and the formation of new friendships (Carter, et al., 2016). However, further research is also indicating additional outcomes related to the perception of school belonging and stress (Ercan, Erginoz, Alikasifoglu, Uysal, Yurtseven \& Fiscina, 2017), supports students with disabilities (Boyle, Topping, Jindal-Snape \& Norwich, 2012; Dolva, Gustavsson, Borell, Hemmingsson, Hälsa \&Vård, 2011), and even supporting students experiencing bullying or trauma (Cowie, 2011, Houlston, Smith \& Jessel, 2011; Turunen \& Punamäki, 2016). According to Coleman, Sykes and Groom (2017), the design and development of PS programs are iterative and responsive to the needs of each location and, as a result, can vary regarding aims, delivery, and structured activities. There are several examples of established peer support programmes currently operating in primary and post-primary schools. One such example, led by Hughes, Guth, Hall, Presley, Dye and Byers (1999), sought to remove barriers to inclusion by providing students with the opportunity to help peers with disabilities 
to "become actively involved in the mainstream of high school life" (pg.32). Known as the

'Peer Buddy Programme', evaluative research continues to show that the provision of social and academic support to students with moderate to severe disabilities has a significant influence on the holistic educational experience and personal growth (Copeland et al., 2004).

\subsection{Introducing Peer Mentoring}

School bullying has become a worldwide concern, with researchers expanding on projects that explore risk and preventive factors (Tzani-Pepelasi Ioannou, Synnott \& Ashton, 2018) or take a novel approach in complementing anti-bullying policies within schools (White, Foody, O’Higgins Norman, 2019). A vast body of research has highlighted the severity and longlasting influences bullying can have, including consequences such as anxiety, loneliness, decreased self-esteem, post-traumatic stress disorder (PTSD), truancy, poor academic performance, alcohol or drug abuse, low social competence, and even suicide (Batsche \& Knoff, 1994; Craig, 1998; Goldbaum, Craig, Pepler \& Connolly, 2003; Graham, Bellmore \& Juvonen, 2003; Kumpulainen, Rasanen, Henttonen, Almqvist, Kresanov, Linna, Moilanen, Piha, Tamminen \& Puura, 1998; Kaltiala-Heino, Rimpela, Marttunen, Rimpela \& Rantanen, 1999; Kochenderfer-Ladd \& Ladd, 2001; Nansel, Overpeck, Haynie, Ruan \& Scheidt, 2003; O'Higgins-Norman, 2009; Olweus, 1993b; O’Moore \& Kirkham, 2001; Minton, Dahl, O’Moore, \& Tuck, 2008; Williams, Chambers, Logan \& Robinson, 1996). Through this research, the topic of school bullying has attracted many researchers who have conducted indepth research to produce efficient and successful anti-bullying models, some of which are discussed below.

Although there are more than 50 well known anti-bullying programs, nonetheless, the implementation of anti-bullying methods brings only a mild to moderate school bullying rate reduction, while some of these strategies can produce opposite results (Ansary, Elias, Greene 
\& Green, 2015). Perhaps this minimal effect comes from the fact that most of the programmes focus on intervention after a school bullying incident occurs, rather than focusing on preventing such incidents from occurring in the first place. Moreover, even if a model successfully prevents or assists in the intervention of bullying, it is possible that schools that struggle financially are unable to acquire such models due to lack of governmental funds (Persson \& Svensson, 2013) necessary for staff training (Williford \& Depaolis, 2016).

One of the most successful anti-bullying programmes, was developed by Olweus (1978), and it is used worldwide for children ages six to fifteen (Yerger \& Gehret, 2011). While some programs focus on aggression replacement training that aims to reduce youths' anger and chronic aggression others, such as the 'Promoting Alternative Thinking Strategies Method' that focuses on social and emotional learning (SEL) and helps children build social and emotional skills. The KiVa program (Williford, Boulton, Noland, Little, Karna \& Salmivalli, 2012), which includes aspects of peer mentoring, is another example and is based on the theory that bullying is a group process, in which the perpetrator behaves aggressively to achieve a higher peer-group status and is reinforced by the apathy of bystanders. It educates students about the importance of peer involvement in stopping bullying and teaches specific behavioural strategies to defend victims in such circumstances (Williford et al., 2012).

While, it could be debated that the field of youth mentoring is no longer in its early development stage, findings from DuBois, Portillo, Rhodes, Silverthorn and Valentine (2011) suggest that there is no single theoretical construct that can evaluate the effectiveness of mentoring programmes. In other words, the range of factors that influence programme development will likely cause some change in the overall programme outcome. For example, while one programme addressing bullying prevention may emphasise the need for behavioural change intervention in individuals who experience bullying, other programmes 
may focus more on whole-school initiatives that focus on perpetrators who are in need of empathy training, while victims receive confidence building (Kousholt \& Fisker, 2015; 2014).

\subsection{Peer Mentoring in the UK}

Numerous studies have been conducted to explore the benefits of PS and prevention programmes in schools (Laghi, Lonigro, Pallini \& Baiocco, 2018; Gregus, Craig, Rodriguez, Pastrana \& Cavell, 2015). Research concerning school-based PS programmes in the UK often takes a broad quantitative approach in identifying PS programmes and comparing each with the aim of identifying similar characteristics (Cowie, Hutson, Oztug \& Myers, 2008; Ttofi \& Farrington, 2012). Houlston, Smith and Jessel (2009), for example, focused on the peer support models implemented in the English primary and secondary schools. Using data from 240 schools (130 Primary; 110 Secondary), of which 186 had peer support schemes, findings suggested that $62 \%$ of schools are using a structured peer support scheme, with models having some common characteristics. The characteristics of these programs included: befriending-based approaches, counselling-based approaches but not so popular, using more than one type of peer support, ongoing training for peer mentors either external or internal, peer mentors tended to be students from their oldest year groups. However, a difference amongst the models appeared to be the focus of the primary schools on outcomes for peer supporters and the whole school, while secondary schools commonly focused on objectives for targeted students.

As mentioned previously, Cowie (2011) highlights PS as being of significant value when it comes to bullying intervention; the adoption of peer support within schools can create opportunities for children and young people to be proactive in challenging bullying when they observe it. Peer supporters are reported to play a vital role in this process by monitoring social interaction during break-times, to support victims by reporting abusive behaviour, and to also 
contribute to standing against negative behaviour online or offline.

The programme that could closely relate to peer mentoring is 'The Steps to Respect Program', which attempts to prevent child abuse, violence, and bullying, by helping elementary school students identify, inform and understand the right to refuse to bully, while focusing on positive attitudes and building positive friendships (Adickes, Worrell, Klatt, Starks, Vosicky \& Moser, 2013).

These forms of peer support models have become an attractive alternative to national and international programmes as they often cover the limitations of other models, there is also the added incentive that they necessitate the use of minimal funding, could be implemented as early as reception year, and function as both a prevention and intervention strategy. Implementation of these locally constructed programmes have received significant attention by researchers who have shown the steps to implementing such a program at schools and the positive effects of peer mentoring from a young age (Elledge, Cavell \& Ogle, 2010; Cowie \& Wallace, 2000; Craig, Gregus, Elledge, Pastrana \& Cavell, 2016). For example, Roach (2014) studied the implementation of such a program with a sample of 372 mentees and a comparison group of 1,249 young people from 22 English schools. This particular peer mentoring program was implemented in 150 schools by a national not-for-profit mentoring and befriending agency and used funds provided by the English Department of Education. The implementation began with members of staff of a school (e.g. teachers) being trained and supported by the agency throughout, by attending training sessions, network events, and receiving guidance materials. In this case, the program functioned more like an intervention strategy and focused on ages nine to twelve. As this programme also aimed to prevent bullying of students at risk, students were referred to the program and matched with an older peer mentor. Following the initial meeting, mentors and mentees were meeting on a one-toone basis, in small groups, or could drop in if there was an urgent need. The agency assisted 
the relationships by providing the school with matching criteria, monitoring the given support and ensuring that the training was sufficient. The guidelines were general and the programme was flexible for teachers and schools to have a say according to their experience and familiarity with the school student network and interaction. If a school did not have referral criteria, then students that wanted to join the programme were simply accepted. After the matching meeting students could meet regularly or not, but there was no obligation attached to force either side to attend such meetings.

Although Roach (2014) found that mentees showed higher levels of life satisfaction and had improved perceptions of school satisfaction, it suggested that the peer support model could be improved in several ways, such as developing better matching criteria or monitoring the activities undertaken during the meetings.

Despite the usefulness of the peer support strategies, the funding for the development of such programs is often minimal (Mead, Hilton \& Curtis, 2001). Nonetheless, peer support systems are becoming more popular anti-bullying strategies in secondary schools, while primary schools are also becoming involved in various ways, where Year 6 children support and build positive relationships with their younger peers. Presently, these various implemented strategies are not integrated into a national network of peer support skills. Therefore, their effectiveness and sustainability depends upon their definition, the training process, support and supervision for the young people (Bishop, 2003). For such programmes to become useful for all schools and educational organisations, more evidence must be collected on how schools that already use peer support, set up and deliver such programs, as well as how these can be improved.

\subsection{The Call from the Government}

In 2017, the Department of Education in the UK (DEUK) wanted to improve mental health 
support in schools, workplaces, and communities, with an emphasis on peer support programs. This development occurred after a Steering Group in 2015 worked on the ways that could improve peer support for mental well-being, and informed that young people prefer to seek assistance from friends/peers, apps/websites; while over $50 \%$ of participants would appreciate both receiving and providing peer support. Therefore, the government wanted to inform schools and organisations on how to set up and run effective peer support programs that promote mental well-being and support children in need. To do that, an assessment of existing successful peer mentoring approaches was essential. As a result, the DE released intentions for such research.

\subsection{Rationale and Aims of this Study}

A sizable proportion of research surrounding peer mentoring in schools, is based on external programmes that may or may not have been retrofitted for the purpose. While being implemented in numerous schools without factoring for the characteristics of the school, another feature that is lacking in PM research is the facilitation of individual schools' Ofsted reports. Similar to $\mathrm{PhD}$ research conducted by McDonnell and Minton (2017), macrosystemic information may reveal important subjective characteristics related to the culture and overarching ethos of a school based on a preexisting framework. As such, standardised Ofsted reports in the UK may be used as a way to highlight factors that influence the implementation of interventions or initiatives within an educational ecosystem. A large number of educational organisations and Governmental Departments are becoming more aware of the importance and value of peer mentoring; such examples are the Department for Education $\left(27^{\text {th }}\right.$ June, 2017), IPPR (2016), and Department of Health (2012).

Therefore, taking into account previous literature that, suggests peer mentoring as potential successful tools for anti-bullying strategies, as well as the positive impact of PS if 
bullying occurs, adding the call from the DE for more research, led to this project. The aim of this study was to provide an insight on the efficiency and functionality of the Buddy Approach as an intervention and prevention anti-bullying tool, as well as a positive addition to schools for improved student satisfaction and supportive environment.

\section{Methodology}

\subsection{School selection criteria}

The particular primary school was chosen for this study, for its outstanding Ofsted report, the previously multiple awards for its ethos, exemplary environment and student achievement, and the low rates of severe verbal and physical bullying. Reported rates of bullying were discussed with the head teacher prior to the commencement of this project, which was crossreferenced with the Ofsted report in terms of Behavior and Safety of Pupils.

\subsection{An Insight into the Buddy Approach}

The Buddy Approach, in the context of this school, has been an official feature and component of the district primary school practices since 2015, while the same practices were always implemented but were more focused more on academic support. Although, traditionally, the role of Year Six children, aged from nine to eleven years old, had always been to act as a mentor and support reception students during class breaks and lunch. The rationale behind this implementation was to assist reception students to feel secure at school, and particularly in the playground, while always having another child that is more familiar with the school practices and facilities to guide and support them. Mentors are typically responsible for one mentee of the same gender, with some element of supervision by the Head Teacher and other trained school staff members. Before being assigned a mentee, mentors are asked whether they know any of the reception students; this process begins during the first 
weeks of each academic year and mentors are responsible for their mentee for that year. However, there are instances where mentors and mentees have been of the opposite sex, and that is mostly in the case of siblings. The head teacher reported that siblings are not always happy to mentor their younger brother or sister; occasionally, there have been instances where this process was seen as a burden for the older child.

Supported by research conducted by Hadfield, Edwards and Mauthner (2006), having a sibling at school can be a source of support when victimised, although, that is not absolute. Often elder siblings long for sibling separateness during school hours, while younger siblings long for exactly the opposite, and expect their older siblings to protect them. However, in this particular school, if a mentor or a mentee does not feel comfortable with each other, the head teacher assigns the mentee to another mentor. This particular peer mentoring functions as a befriending scheme where peer supporters are trained to offer friendship or informal support (see Cowie, 2011). Finally, mentees are advised to seek guidance, advice, and support from their mentors whenever they feel the need. Whereas mentors, amongst various responsibilities, are also advised to support their mentees by 'keeping an eye on them', particularly the first few weeks while in reception. As a fundamental component of the programme, mentors are advised to often assist mentees with tasks and maintain frequent communication during break time, lunchtime, and reading time. The range of tasks can vary based on practical supports, such as getting their school dinner and getting to know the school facilities and can also act as a psychological support, by providing friendship and helping the mentees socialise either by playing with them or introduce them to other peers. Another feature is to intervene when they witness incidents of verbal or physical bullying by informing the teachers and comforting the mentee-victim.

Moreover, mentors are advised to be mostly vigilant during break time, particularly when students engage in free play without adult supervision. During such times, mentors 
address signs of verbal or physical bullying, or potential accidents, such as falling, in addition to responding to other needs of guidance and support. In cases where mentees need support, if a mentee is feeling lonely or isolated, the mentor is advised to play with the mentee or assist the mentee in finding a suitable peer group to socialise with. However, instances where more serious events occur, such as bullying, the mentor attends to the mentee but also informs a member of staff to address the matter. Having informed a member of staff, the mentors' role is to function as a source of comfort and security. As mentees become more comfortable in the school environment and form their own peer groups, the need for a mentor gradually decreases. However, mentors remain available till the end of the academic year, should the mentees require support, assistance or guidance.

Concluding, each mentee exhibits different needs at the beginning of the academic year. Some mentees require assistance during lunchtime, some others find the separation from their family difficult and may become isolated, some require more guidance in terms of school facilities, and some need advice regarding the ethics and boundaries in terms of appropriate behaviour at school. Consequently, mentors address these various needs, but also discuss each case with the head teacher and other trained staff members, on a frequent basis to decide on the best plan of action and support.

\subsection{Participants}

Due to the nature of this research, a purposive sampling strategy was utilised for this primarily qualitative research. A total of twenty-nine students were interviewed $(\mathrm{N}=29 ; \overline{\mathrm{x}}=$ 6.72; $S D=2.76)$. Nineteen $(n=19)$ reception students (mentees) were interviewed out of which, ten were female and nine male; with ages ranging from four years old to five years old $(\overline{\mathrm{x}}=4.79, S D=0.41)$. Each of the reception students received mentoring from a Year Six student mentor. From Year Six, ten students $(n=10)$ (mentors) were interviewed; which two 
were female and eight were male; ages varied between nine years old and eleven years old ( $\overline{\mathrm{x}}$ $=10.4, S D=.69)$. It must be clarified, that it is not known if some of the interviewed mentors mentored some of the interviewed mentees. Both parties were not asked who their mentor/mentee was for confidentiality issues. Although a purposive sampling technique was utilised, participant recruitment relied on parental consent, which could not be controlled, consequently, the sample was not normally distributed in terms of gender.

\subsection{Procedure}

Upon receipt of the participant and parental consent, an initial timetable was developed and approved by the Head teacher to ensure minimal disruption to teaching and learning of the school. Due to the school schedule, interviews were conducted either in the library of the school or a room where teachers use for planning and preparation. In line with ethical guidelines, a senior teacher was present throughout each interview. The interviews took place over a nine day period to cause as little disruption to the teaching and learning curriculum as possible. First, the reception-student/mentees were interviewed over five working days, followed by the remaining Year Six student mentors over four working days. The duration of each interview was between 15-20 minutes, with the format being mirrored for both participant groups. Each participant was asked once more if they were willing to be interviewed, assured that they can ask to stop at any time, and informed of the rationale for this research. They were asked to discuss their experience of the peer buddy programme based on the series of questions (discussed below), and were then given a full debrief and sealed envelope for their parents/guardians, which contained a written debrief and a token of appreciation (a book) for their child for participating in this research.

\subsection{Measurement tools}

An initial open-ended questionnaire was developed by the research team, which was reviewed 
by the head teacher prior to the interviews taking place. The interview questions were developed in an age appropriate way, and the parental consent forms provided a full overview of the research and the rationale. Minor changes to the questionnaire were made having received feedback. The final version of the questions included items such as "do you like being a mentor?" or "how do you see your buddy, is your buddy your friend or kind of like a grown-up?" and was used with mentees and mentors mostly as a guide informing the semistructured interviews. It should also be noted that many questions related to how students perceive the buddy approach, as well as its efficiency and functionality (e.g. What does your buddy help you with, how, and how does that make you feel). Finally, mentees and mentors were asked about their experiences of bullying at school. According to the head teacher, the bullying terminology used at the particular school, defines bullying as any verbal or physical act that causes harm, sadness, discomfort, loneliness, and teasing or spreading rumours about someone.

Students are frequently reminded of this unacceptable/unwanted behaviour and posters are exhibited in most areas of the school stating the above. Consequently, the research team followed the head teacher's bullying terminology to interview the students, but to cover the repetition criterion supported by Olweus (1993b), asked the ones that reported teasing or bullying, if the person who did the teasing or the bullying has done it more than once. Both mentors and mentees were only audio-recorded during the interviews.

\subsection{Analysis}

Once all interviews were completed, each was transcribed and coded using thematic analysis, as outlined by Braun and Clarke (2006). To ensure rigour throughout this process, the data was blinded and independently reviewed by two additional researchers who confirmed the identified themes. 


\subsection{Ethics}

This research received ethical approval from the Faculty of Human and Health Science Research Ethics Committee; also the Head teacher and participants' parents reviewed and approved the interview questions. To align with the ethical guidelines concerning research with participants under the age of 18 , the interviewing took place in a room within the main school building. Both the student and their parent/guardian completed consent forms, in addition to providing full briefing and debriefing. In line with ethical guidelines, a senior teacher was present throughout each interview. To avoid increasing mentees' anxiety, due to a traumatic experience such as bullying, the member of staff that was present during the interviews had also been given permission to become involved in the process and stop the interview if the mentee showed signs of discomfort (e.g. crying). However, no such incidents occurred. The students are motivated and supported from day one at school, to freely express their feelings and thoughts. It is possible that the mentees perceived the interview process as an incorporated process to the school's procedures and, therefore, felt secure to discuss these matters. Whereas, the mentors felt proud to talk about the program, as it can be seen in the thematic analysis.

\section{Results}

This study focused solely on exploring one example of a peer-mentoring programme supported by the particular's school head teacher as a functional, sustainable with a positive impact on the school and students approach. The history regarding the implementation and positive impact the programme has had on the school was highlighted after an initial discussion and interview with the head teacher, who stated: 
"This program has been used in this school for many years and we receive positive feedback every year. Parents tell us that their children enjoy it, little ones feel safe and they have a friend to talk to, and older ones feel that we are teaching them responsibility in a constructive way ... Over the years, this approach became a permanent component of the school's processes and we have received positive feedback regarding student satisfaction".

Based on the thematic analysis, several themes were identified and explored the 'Comprehensive Mentor Training' and the 'Positive School Experience' the programme brings to the school community, and the 'Emotional Development' and 'Personal Growth' felt by both the mentors and mentees. The final theme, relating to 'School Bullying Prevention and Intervention', elaborates and gives further insight into the existing criteria and frameworks in the context of this research, and applied to organisations and governmental departments.

\subsection{Comprehensive Mentor Training}

Throughout the interviews with the mentees and mentors, numerous situations are mentioned where mentees were experiencing personal distress that was quickly resolved by a mentor. While these interactions only provide a glimpse of the relationship between the mentor and the mentee, they demonstrate that the mentor programme has great potential in terms of effectiveness, particularly, if it can be considered as a holistic approach that could potentially provide social and academic support, friendship to reception students, as well as training to mentors. In one interview, a mentee explains that her friends are mostly girls because they are kind, compared to boys. This statement implies some negative experience involving male students. The mentee reports that her buddy is a boy, but she likes him, because he helps her when she is lonely by playing with her and by "being funny". This level of emotional support 
is indicative of a mentor analysing the situation and then employing a personalised strategy to support the mentee. Mentee D2 then discusses a particularly negative scenario where she was supported by her buddy:

"Year 4 children teased me because I have hair on my face and above my lips, and my buddy helped me. He told the teacher, and the teacher warned the boy who teased me, and he never teased me again. Teasing me made me feel not happy. But I am very happy because my buddy is here to protect me” (Mentee D2)

While the sole function of a mentor is to support the mentee, this example shows how the approach and training have the potential to be reflexive, in supporting mentors when dealing with a variation of mentees' needs. The mentor recognised that his mentee was upset as a result of a more serious incident that, was beyond his capacity and immediately sought support from an adult. It is also an example of how this student starts to shift perceptions of generalisability. This training is further evident in another example where the mentee explained that "another child pushed me, and my buddy told the teacher, and that made me feel happy and safe when someone is mean to me my buddy protects me" (Mentee D3).

Although, the head teacher had stated that rarely there is a bullying incident in the particular school, capturing the students' voice and experience of the buddy approach signifies the role it can have within an anti-bullying strategy (Cowie, 2011). However, it also must be designed in such a way that teachers and the school staff remain the senior and official line of any strategy implementation for bullying prevention and intervention.

\subsection{Positive School Experience}

Leading on from training, it is clear that interactions with mentees and mentors have a 
significant impact on school experience. As reported above, support in school can improve the school experience and increase the well-being of students. The majority of mentees reported, valuing their buddies' assistance and enjoying spending time together during lunchtime or playing. This relationship indicates positive role modelling, and how providing younger students with someone to look up and supported by, can significantly enhance school experience. For example, one mentee mentions that his buddy and his buddy's friends are among the friends that he likes, despite seeing them as grown-ups. Continuing to mention that his mentor "helps me when I am lonely, and finds me and lets me play in the football court"; this student highlighted experiencing some bullying and that although his mentor was unavailable at the time, "I saw my buddy I went to him, and he told me not to be sad ... he makes me feel not lonely ... [and] when my buddy helps me and is around I feel happy” (Mentee J1). While several other mentees also use expressive and emotional language, such as being 'lonely' or 'sad', this promptly changed to feeling 'happy' and 'safe' when speaking about their experiences with their buddy.

The interviews with the mentors confirmed how the mentees developed throughout the year and supported their mentees with academic and personal issues that arose. While several mentors reported that mentees often experience loneliness initially, one mentee explained that when his mentee "came in [to school], he was alone and didn't speak to anyone, but now he trusts me and comes with me and has built his confidence and has friends also... now he doesn't come to me so often" (Mentor J3). This is further elaborated by another mentor, who highlights that they began to notice their mentee being more comfortable because they were needed less as the year continued, "I think I helped him a lot the first few days because he started later than the others but now he is all right" (Mentor A2). The support of mentors enables mentees to experience a completely new environment in a positive, safe, and supportive way. 


\subsection{Emotional Development}

Peer mentoring programs have been shown to spread empathy and emotional awareness among the students (Channon et al., 2013). In several instances, mentees reported expressing sadness when speaking of their mentors' departure when they graduate to for another school; "I really like my buddies, but they are leaving, and that makes me sad because I will not have anyone else" (Mentee J1). Although this is consistent with other research (Carter et al., 2016), it is interesting to note that one mentee, in particular, reported that her mentor "helps me think about people that are not really nice to me and that makes me feel really happy" (Mentee A4). In further discussion, the student clarified that thinking about people that are not nice and having someone to talk to about it, made the student feel happy. It it also evident that pride and happiness are felt when mentors see their mentees overcome difficulties. For example, one mentor explained how his mentee had an accident and came to him for help and that process "made me feel really good and responsible and quite proud of myself actually" (Mentor J1). Research has also indicated that peer interaction increases through these mentoring approaches. This example clearly exhibits a bond between the two groups and perhaps if the opportunity presented could even become a long-lasting friendship.

The emotional maturity of the mentors is evident; one mentor explains that "it's really nice to spend time with them [mentees]" and that "although sometimes we might not understand them very well they understand you and they look up to you and their respect is very valued" (Mentor J1). In one other interview, a mentor was discussing how her initial tasks involved showing her mentee around the playground, but that her mentee soon became 'pretty independent' and needed less support. The mentor then mentioned that, despite not needing as much help, if her mentee came to her "for other reasons apart from playing I would think how to act before I really do" (Mentor L4). 


\subsection{Personal Growth}

While several mentors highlighted that being a mentor makes them feel happy and proud for supporting younger students, there were several examples of mentors reporting varying levels of personal growth from having participated in this experience. Mentor D6 for example, mentions that they "learned a lot this year ... Like being more aware of how people cope with stuff and I learned how to be more considerate and responsible" (Mentor D6), while another mentor expresses feeling proud of how much their mentee has developed over the year and that they feel they "had a positive impact" (Mentor J3) on their mentee.

There are numerous examples of how expressive and intimate the relationships between a mentee and their mentor can be and other instances where mentors are not needed by their mentee at all or in some situations. In one interview, this dynamic was interlinked in ways by the mentee reporting having to experience bullying; "sometimes some people are mean to me, and they push me ... but I don't tell my buddy I go and tell my teacher'. While this is insightful and may elude to the mentee being independent or not wanting peer support, the mentee follows this statement sometime later by mentioning "she [his mentor] helps me cut up my dinner" (Mentee M5). This example is evident of how complex and resilient the young mentees can be in ways, and yet how simple the support needed can be. There were other instances of how initial interactions revolved supporting the mentee throughout their experiences of being bullied, but also how some mentees quickly follow this up with positive affirmations. For example, Mentee R6 describes how his mentor "helps me when I fall over, and he takes me to the teacher" and also "protects me from people who are mean to me" but then also mentions "I am a strong boy you know".

As several mentees express not needing 'help' or 'protection' from their mentor, reporting being able to handle some situations themselves, mentors discuss how some 
mentees become more resilient and better able to support themselves:

"I don't need to do it now as much as at the beginning. Back then I liked helping, and I was fine with it, but now I feel good because she has more friends... My mentee is quite strong now” (Mentor D6).

The level of growth by the mentors is also evident. It was mentioned that, "children who are younger are not very aware of their actions" and that they "do see some pushes etc. but nothing serious" (Mentor J1), they still view the situation as serious to their mentee. As the year progresses, while mentees make friends and settle into the school, the mentors reported that their mentees although sometimes "fall down and are hurt, they just get back up and deal with it" (Mentor J3).

\subsection{School Bullying Prevention and Intervention}

The interviews with the reception students revealed three distinct themes in terms of bullying:

4.5.1. Bullied (minimal verbal teasing and/or pushing). From the mentees' group, nine students $(\mathrm{N}=9)$ testified that they value their buddy's protection when it comes to bullying incidents. On the one hand, it is apparent how the mentee feels secure knowing that there is a supporting figure apart from teachers, allowing them to seek assistance if bullying occurs; on the other, the programme's bullying intervention functionality is evident. A distinctive example was mentee $\mathrm{R} 1$ who reported:

"My buddy protects me from people who are mean to me because sometimes they push me but not a lot. Sometimes they are boys and sometimes are girls. My buddy sees that and he comes to me and picks me up and takes me to the teacher and that makes me feel happy". 
Other mentees showed that they long for interaction with their buddy and also seek protection from their buddy when bullying incidents occur (see mentee D2).

4.5.2. Bullied but Resilient. To this group, four mentees were assigned $(\mathrm{N}=4)$. These young individuals showed that they do not seek protection, and they feel confident to resolve the bullying incident themselves. For example, M1 stated:

"Sometimes some people are mean to me and they push me to stones and things. I don't go to my buddy for help. I will be ok. I am very strong and I can lift a tire. Sometimes I push them and hit them back when they are mean to me. Sometimes I want to play by myself"'.

Although the mentee's resilience and sense of independence are quite evident in this example, still it can be seen how a mentor can be of value under such circumstances. This particular case may be perceived as reactive bullying, and having a role model at school that is aware of the school's policies and behavioural boundaries, could potentially stop the bullying cycle, through peer discussion and advice. In this case, if a teacher were to intervene and "tell off" the reactive bully, the results could be quite the opposite from bullying repetition prevention. Whereas, if the reactive bully is advised and guided by the mentor who is not perceived as an adult authority figure, perhaps reactive bullying and repetition could be avoided. However, from the findings of the present study, this cannot be known, as it was not the focus of the interviews.

4.5.3. Not Bullied. To the last group, there were six students/mentees; these students supported that they value their buddy's company but they had not been bullied, in-spite of exclusion incidents occurring. Therefore, the mentors for this group of mentees functioned more as companions, rather than bullying prevention and intervention figures. One such example was provided by mentee $\mathrm{J} 1$ who described other types of interaction apart from 
potential prevention or intervention if bullying occurs.

"Helps me when I must go to gymnastics ... helps me when I am lonely and finds me and let me play in the football court",

\section{Discussion}

The development of peer mentoring and bullying interventions have been widely documented and evaluated across the literature (Adickes et al., 2013; Cowie et al., 2008; Houlston et al., 2009; Williford et al., 2012; Yerger \& Gehret, 2011). Although there is growing evidence indicating that the peer buddy approach functions well, as an anti-bullying method in a wide variety of settings (Naylor \& Cowie, 1999; Houlston et al., 2011); nonetheless, Bishop (2003) reported that the effectiveness and sustainability is dependent upon many factors (p.33). In one study, Roach (2014) identified the programme characteristics of peer mentoring programmes in five primary and 11 secondary schools based in England. Wide variance between the programmes was indicated, including mentoring design, such as drop-in or oneto-one, or in mentor selection, such as self-selection or programme coordinators.

Additionally, it was shown that most programmes operated on a mentee self-referral basis, some matching of mentors and mentees took place, and only a small number of schools provided mentors with suggested activities and resources for mentors to use throughout the process. In the discussion of the research, Roach (2014) identified the limitations of using self-report measures in the absence of other methodological techniques, how some research may associate the frequency of mentor and mentee meetings with the quality of the relationship, or how differences in characteristics of each programme operating in a school can nuance the statistical findings.

The findings from this study are consistent with other research, confirming that the peer buddy approach can improve students' experience and also function as a significant 
influence on bullying prevention (Bishop, 2003). While, previous research has focused on quantitative measures to evaluate programmes, such as the 'Satisfaction Scales' (Huebner, 1991; 1994) or 'Strength and Difficulties Questionnaire' (Goodman, 1997), this research takes a qualitative approach and highlights the importance of qualitatively-led research in exploring the lived experience and student-voice concerning peer mentoring programmes. The rationale for this approach is made evident, when considering how some mentees reported feeling protected and safe by having a mentor around, when in need. Additionally, it is likely that a quantitative approach concerning peer mentoring at school would not have provided mentors with the opportunity to discuss their opinions and perspectives should they observe bullying.

Research by Cowie (2011), for example, reported that PS creates opportunities for children and young people to be proactive in challenging bullying when they observe it. While, it is reported that this particular school does not experience severe bullying incidents, a qualitative approach emphasises the background culture of how students are pro-active and motivated to report such incidents. It also shows that, students are appraised for their bravery and courage when reporting such incidents. In addition, it gives insight into how the school's staff resolves situations individually and immediately by using restorative practices techniques. The buddy approach functions as an intervention method for bullying while, in the long run could function as a prevention method.

Regarding practical strategies for peer mentoring programme design, this research offers several suggestions. Roach (2014) reports that students participating in mentoring were more likely to experience bullying than the control group. Although not considered statistically significant, it is mentioned that students participating in mentoring may be more perceptive of what may be considered bullying and report it more, or that some mentoring programmes may not have been effective at targeting bullying prevention. Although mentees 
reported experiencing elements of bullying or other students behaving mean towards them, several mentors also expressed how some interactions they witnessed were 'accidents'. The differences and contrasted experiences of mentees and mentors can be restrictive in quantitative methodological research and can be a limitation within large-scale evaluations. Not only does this current research provide insight into programme design, and how it may be beneficial to standardise the process of peer mentoring, it also promotes the importance of training and the interaction between mentees and mentors; which has been lacking in previous research. For example, it appears that the more a mentor embraces their role and responsibility, the more their relationship with the mentee appears stronger and increases the frequency of interactions. This interaction, occurs either by the mentee seeking for the mentor's attention and then the mentor reciprocating or the mentor seeing an opportunity to converse or 'check-in' on the mentee. Regardless of the way interaction is initiated, the process of supporting the mentee is likely a significant influence on both the mentee and the mentor's well-being. For mentors, while participation in peer mentoring influenced feelings of pride and satisfaction as a result of supporting their mentee, it may also positively influence empathy and encourage pro-social behaviour in the future as a result supporting younger students in need.

It is accepted that previous studies (Cowie, 1998; Houlston \& Smith, 2010; Roach, 2014; Vreeman \& Carroll, 2007) found various difficulties with the implementation of such approaches, such as no overall effect on bullying levels, peer intervention when witnessing bullying, requiting mentors and particularly males, planning of the approach, despite the fact that accepted the potential efficacy of such approaches. To this, it could be suggested that the number of years of the approach's implementation in this specific school may have played a role in the positive effects. Initially, in the development of the programme, it is possible that mistakes occurred, and students might have not been active in participating. Also, it is 
possible that the staff lacked sufficient training. However, over the years, the head teacher and the staff, reflected upon such mistakes, thus resulting in continuous improvement of the approach. While, new students might have begun to perceive this approach as a common policy or practice of the school, thus, accepting it from the start.

\section{Conclusion.}

While, previous research has focused on quantitative measures to evaluate programmes, such as the 'Satisfaction Scales' (Huebner, 1991; 1994) or 'Strength and Difficulties Questionnaire' (Goodman, 1997), this research took a qualitative approach and highlighted the importance of qualitatively-led research in exploring the lived experience and studentvoice concerning peer mentoring programmes. The rationale for this approach is made evident when considering how some mentees reported feeling protected and safe by having a mentor around when in need. Additionally, it is likely that a quantitative question concerning bullying at the school would not have given some mentors the opportunity to speak hypothetically and report how, if they witnessed bullying, they would interfere and report that incident to a teacher. Regarding limitations, the mentees' age presented a challenge particularly for interviews of this type. Although, it was aimed to keep interviews concise, students often began to discuss topics outside the remit of this research and found it difficult to stay on task. As it was the end of the academic year and the Year Six students were preoccupied with their exams, the sample size is another consideration. However, an auxiliary aim of this research was to showcase the importance of qualitative research concerning peer mentoring, which is believed to be achieved. For future research, a combination of qualitative and quantitative methodologies would be beneficial. For example, an experimental design that adopts a student-voice approach in interviews but also uses pre-and-post intervention measures, as identified above, would offset the numerous limitations within this research 
field.

Moreover, it is possible that the level of the approach's success is ought partially to mediating factors, such as the area where the school was, which is perceived as a relatively safe area to reside, inhabited by mostly families and pensioners. Additionally, this project examined the buddy approach in one primary school; consequently, it is not known how this approach would function in higher levels of education. Previous research (Elledge, Cavell, Ogle \& Newgent, 2010) demonstrated the various difficulties of implementing the same peer support model in all stages of education, consequently, it is suggested that the implementation of this approach in secondary school should be with caution, while further research is required to establish mediating factors that could assist or harm the approach's efficacy. Finally, it would also be insightful to conduct interviews at the start and the end of each academic programme with the aim of recording the impact of the peer mentoring approach in terms of behaviour differences, school experience, and overall perception of the educational environment.

The findings of this research can assist in developing an effective peer support model,framework for implementation, or added programme for anti-bullying policies. As reported in several studies above, bullying in schools can have a significant negative influence on the student experience and contribute to perceptions of anxiety, lowered self-esteem, or isolation. In addition to functioning as bullying intervention and prevention, this research has shown that programmes adopting a buddy approach could also assist in the promotion of student well-being. For example, the wider benefits are articulated by one mentor in this research who argues that programmes such as these are "a good idea because we get to help the little people because they need us, but even if they didn't they would still know that we are there and they can come to us" (Mentor L4). The wider range of benefits peers can provide for younger students surround the importance of facilitating positive educational experiences 
to students and promoting inclusion in all aspects. The recipricol relationship nurtured through these programes can assist students in becoming more confident, with an increased sense of responsibility and morals; particularly when caring for their fellow peers. As a result, this research supports other recent works in this area (White, Foody, \& Norman, 2019; TzaniPepelasi Ioannou, Synnott \& Ashton, 2018) and further highlights the evident role peer relationships can have; especially in terms of policy development and whole-school initiatives that promote positive educational experiences.

\section{References}

Adickes, J., Worrell, K., Klatt, C., Starks, J., Vosicky, A., \& Moser, C. S. (2013). Bullying. Journal of Occupational Therapy, Schools, and Early Intervention, 6(1), 1-13. doi:10.1080/19411243.2013.771099.

Ansary, N. S., Elias, M. J., Greene, M. B., \& Green, S. (2015). Best practices to address (or reduce) bullying in schools. Phi Delta Kappan, 97(2), 30.

Batsche, G.M. \& Knoff, H.M. (1994 ). Bullies and their victims: Understanding a pervasive problem in schools. School Psychology Review, 23(2), 165-174.

Bishop, S. (2003). The development of peer support in secondary schools. Pastoral Care in Education, 21(2), 27-34. doi:10.1111/1468-0122.00259.

Boyle, C., Topping, K., Jindal-Snape, D., \& Norwich, B. (2012). The importance of peersupport for teaching staff when including children with special educational needs. School Psychology International, 33(2), 167-184. doi:10.1177/0143034311415783.

Braun, V., \& Clarke, V. (2006). Using thematic analysis in psychology. Qualitative research in psychology, 3(2), 77-101. doi: 10.1191/1478088706qp063oa.

Carhill-Poza, A. (2017). "If you don't find a friend in here, it's gonna be hard for you":

Structuring bilingual peer support for language learning in urban high schools.

Linguistics and Education, 37, 63-72. doi:10.1016/j.linged.2016.09.001. 
Carter, E. W., Asmus, J., Moss, C. K., Biggs, E. E., Bolt, D. M., Born, T. L., . . W Weir, K. (2016). Randomized evaluation of peer support arrangements to support the inclusion of high school students with severe disabilities. Exceptional Children, 82(2), 209-233. doi:10.1177/0014402915598780.

Carter, E. W., Gustafson, J. R., Sreckovic, M. A., Dykstra Steinbrenner, J. R., Pierce, N. P., Bord, A., .. . Mullins, T. (2016). Efficacy of peer support interventions in general education classrooms for high school students with autism spectrum disorder. Remedial and Special Education, 74193251667206. doi:10.1177/0741932516672067.

Cavadel, E. W., \& Frye, D. A. (2017). Not just numeracy and literacy: Theory of mind development and school readiness among low-income children. Developmental psychology, 53(12), 2290.

Channon, S., Marsh, K., Jenkins, A., \& Robling, M. (2013). Using motivational interviewing as the basis for a peer support programme in high school. Pastoral Care in Education, 31(1), 66-78. doi:10.1080/02643944.2012.731426.

Children's Commissioner. (2018). Forging Futures through Mentoring: A Risk Worth Pursuing. Retrieved from https://www.childrenscommissioner.gov.uk/publication/mentoring/.

Chong, W. H., Huan, V. S., Yeo, L. S., \& Ang, R. P. (2006). Asian adolescents' perceptions of parent, peer, and school support and psychological adjustment: The mediating role of dispositional optimism. Current Psychology, 25(3), 212-228. doi:10.1007/s12144-006-1004-6.

Coleman, N., Sykes, W., \& Groom, C. (2017). Peer Support and Children and Young People's Mental Health: Research Review. Government Social Research, Department of Education. 
https://assets.publishing.service.gov.uk/government/uploads/system/uploads/attachme nt_data/file/603107/Children_and_young_people_s_mental_health_peer_support.pdf

Copeland, S. R., Hughes, C., Carter, E. W., Guth, C., Presley, J. A., Williams, C. R., \& Fowler, S. E. (2004). Increasing access to general education: Perspectives of participants in a high school peer support program. Remedial and Special Education, 25(6), 342-352. doi:10.1177/07419325040250060201.

Cowie, H. (2011). Peer support as an intervention to counteract school bullying: Listen to the children. Children \& Society, 25(4), 287-292. doi:10.1111/j.10990860.2011.00375.x.

Cowie, H., \& Wallace. P. Peer Support in Action : From Bystanding to Standing By, SAGE Publications, 2000. ProQuest Ebook Central, https://ebookcentral.proquest.com/lib/HUD/detail.action?docID=254712.

Craig, W. M. (1998). The relationship among bullying, victimization, depression, anxiety, and aggression in elementary school children. Personality and Individual Differences, 24(1), 123-130. doi:10.1016/S0191-8869(97)00145-1.

Department for Education. (27 $7^{\text {th }}$ June, 2017). PM: mental health training for teachers will "make a real difference to children's lives". [Press release]. Retrieved from https://www.gov.uk/government/news/pm-mental-health-training-for-teachers-willmake-a-real-difference-to-childrens-lives.

Department of Health. (2012) Future in mind. Promoting, protecting and improving our children and young people's mental health and wellbeing. Retrieved from https://www.adhdfoundation.org.uk/wp-content/uploads/2017/05/ChildrensMental-Health-Report-2015-1.pdf. 
Dolan, P., Brady, B., O’Regan, C., Russel, D., Canavan, J., \& Forkan, C. (2010). Big Brothers Big Sisters (BBBS) of Ireland: Evaluation Study [Report 1]. Retrieved 08/08/20118 from https://www.foroige.ie/sites/default/files/BBBS\%20Report\%201.pdf .

Dolva, A., Gustavsson, A., Borell, L., Hemmingsson, H., Hälsa, A., Vård (HAV), Linköpings universitet, . . Hälsouniversitetet. (2011). Facilitating peer interaction - support to children with down syndrome in mainstream schools. European Journal of Special Needs Education, 26(2), 201-213. doi:10.1080/08856257.2011.563607.

DuBois, D. L., Portillo, N., Rhodes, J. E., Silverthorn, N., \& Valentine, J. C. (2011). How effective are mentoring programs for youth? A systematic assessment of the evidence. Psychological Science in the Public Interest, 12(2), 57-91.

Elledge, L.C., Cavell, T.A., Ogle, N.T. et al. J Primary Prevent (2010) 31: 171. https://doi-org.libaccess.hud.ac.uk/10.1007/s10935-010-0215-7.

Elledge, L. C., Cavell, T. A., Ogle, N. T., Malcolm, K. T., Newgent, R. A., \& Faith, M. A. (2010). History of peer victimization and children's response to school bullying. School Psychology Quarterly, 25(2), 129-141. doi:10.1037/a0020313.

Ercan, O., Erginoz, E., Alikasifoglu, M., Uysal, O., Yurtseven, E., \& Fiscina, B. (2017). Connections? peer support, liking school, and schoolwork pressure. Journal of Adolescent Health, 60(2), S51. doi:10.1016/j.jadohealth.2016.10.284.

Ttofi, M. M., \& Farrington, D. P. (2012). Bullying prevention programs: The importance of peer intervention, disciplinary methods and age variations. Journal of Experimental Criminology, 8(4), 443-462. Doi: 10.1007/s11292-012-9161-0.

Roach, G. (2014) A Helping Hand? A Study into an England-wide Peer Mentoring Program to Address Bullying Behavior, Mentoring \& Tutoring: Partnership in Learning, 22:3, 210-223, DOI: 10.1080/13611267.2014.926663.

Goldbaum, S., Craig, W.M., Pepler, D., \& Connolly, J. (2003). Developmental trajectories of 
victimization: Identifying risk and protective factors. Journal of Applied School Psychology, 19(2), 139-156. doi:10.1300/J008v19n02_09.

Graham, S., Bellmore, A., \& Juvonen, J., (2003). Peer victimization in middle school: When self- and peer views diverge. Journal of Applied School Psychology, 19(2), 117-137. doi:10.1300/J008v19n02_08.

Gregus, S. J., Craig, J. T., Rodriguez, J. H., Pastrana, F. A., \& Cavell, T. A. (2015). Lunch buddy mentoring for children victimized by peers: two pilot studies. Journal of Applied School Psychology, 31(2), 167-197. Doi: 10.1080/15377903.2015.1025172.

Hadfield, L., Edwards, R., \& Mauthner, M. (2006). Brothers and sisters: A source of support for children in school? Education 3-13, 34(1), 65-72. doi:10.1080/03004270500507602.

Henry, L. A., Castek, J., O'Byrne, W. I., \& Zawilinski, L. (2012). Using peer collaboration to support online reading, writing, and communication: An empowerment model for struggling readers. Reading \& Writing Quarterly, 28(3), 279-306.

Houlston, C., Smith, P. K., \& Jessel, J. (2009). Investigating the extent and use of peer support initiatives in english schools. Educational Psychology, 29(3), 325-344. doi:10.1080/01443410902926751.

Houlston, C., Smith, P. K., \& Jessel, J. (2009). Investigating the extent and use of peer support initiatives in English schools. Educational Psychology, 29, 325-344.

Houlston, C., Smith, P. K., \& Jessel, J. (2011). The relationship between use of schoolbased peer support initiatives and the social and emotional well-being of bullied and non-bullied students: Peer support influences. Children \& Society, 25(4), 293-305. doi:10.1111/j.1099-0860.2011.00376.x.

Huebner, E. S. (1991). Initial development of the student's life satisfaction scale. School Psychology International, 12, 231-240. 
Huebner, E. S. (1994). Preliminary development and validation of a multidimensional life satisfaction scale for children. Psychological Assessment, 6, 149-158.

Hughes, C., Guth, C., Hall, S., Presley, J., Dye, M., \& Byers, C. (1999). They are my best friends: Peer buddies promote inclusion in high school. Teaching Exceptional Children, 31, 32-37.

IPPR. (2016) Education, education, mental health: Supporting secondary schools to play a central role in early intervention mental health services. Retrieved from http://www.ippr.org/files/publications/pdf/education-education-mentalhealth_May2016.pdf?noredirect=1.

Craig, J.T., Gregus,. S. J., Elledge, C. L., Pastrana, F.E., \& Cavell, T. A. (2016). Preliminary investigation of the relation between lunchroom peer acceptance and peer victimization, Journal of Applied Developmental Psychology, 43, (101).

Kaltiala-Heino, R., Rimpela, M., Marttunen, M., Rimpela, A., \& Rantanen, P. (1999). Bullying, depression, and suicidal ideation in Finnish adolescents: School survey. British Medical Journal, 319(7206), 348-351.

Kochenderfer-Ladd, B., \& Ladd, G.W. (2001). Variations in peer victimization: Relations to children's maladjustment. In J. Juvonen \& S. Graham (Eds.). Peer harassment in school: The plight of the vulnerable and the victimized, (pp. 25-48). New York: The Guilford Press.

Kousholt, K., \& Fisker, T. B. (2015;2014;). Approaches to reduce bullying in schools - A critical analysis from the viewpoint of first- and Second-Order perspectives on bullying. Children \& Society, 29(6), 593-603. doi:10.1111/chso.12094.

Kumpulainen, K., Rasanen, E., Henttonen, I., Almqvist, F., Kresanov, K., Linna, S.L., Moilanen, I., Piha, J., Tamminen, T., \& Puura, K., (1998). Bullying and psychiatric symptoms among elementary school-aged children. Child Abuse and Neglect, 22(7), 
705-717. doi:10.1016/S0145-2134(98)00049-0.

Laghi, F., Lonigro, A., Pallini, S., \& Baiocco, R. (2018). Peer Buddies in the Classroom: The Effects on Spontaneous Conversations in Students with Autism Spectrum Disorder. In Child \& Youth Care Forum (pp. 1-20). Springer US. Doi: 10.1007/s10566-0189449-y

Marshall, L., \& Smith, N. (2018). Supporting Mental Health in Schools and Colleges: Pen portraits of provision. National Centre for Social Research. https://assets.publishing.service.gov.uk/government/uploads/system/uploads/attachme nt_data/file/705083/Supporting_Mental-Health_pen_portraits.pdf.

Minton, S. J., Dahl, T., O’Moore, A. M., \& Tuck, D. (2008). An exploratory survey of the experiences of homophobic bullying among lesbian, gay, bisexual and transgendered young people in Ireland. Irish Educational Studies, 27(2), 177-191. Doi: 10.1080/03323310802021961.

McDonnell, D.P., \& Minton, S.J. (2017). An Exploration into the Psychology of Education: The Use of an Ecological Framework to Address Macro and Microsystemic Factors that Influence Individuals Working within Irish Education [Doctoral Dissertation]. Trinity College Dublin, Ireland. doi: 10.13140/RG.2.2.22114.22723.

McVey, G. L., Lieberman, M., Voorberg, N., Wardrope, D., \& Blackmore, E. (2003). School-based peer support groups: A new approach to the prevention of disordered eating. Eating Disorders, 11(3), 169-185. doi:10.1080/10640260390218297.

Mead, S., Hilton, D., \& Curtis, L. (2001). Peer support: A theoretical perspective. Psychiatric Rehabilitation Journal, 25(2), 134-141. doi:10.1037/h0095032.

Nansel, T. R., Overpeck, M.D., Haynie, D.L., Ruan, J., \& Scheidt, P.C. (2003). Relationships between bullying and violence among U.S. youth. Archives of 
Pediatric and Adolescent Medicine, 157(4), 348-353.

doi:10.1001/archpedi.157.4.348.

Naylor, P., \& Cowie, H. (1999). The effectiveness of peer support systems in challenging school bullying: The perspectives and experiences of teachers and pupils. Journal of Adolescence, 22(4), 467-479. doi:10.1006/jado.1999.0241.

O'Higgins-Norman, J. (2009). Straight talking: Explorations on homosexuality and homophobia in secondary schools in Ireland. Sex Education, 9(4), 381-39. Doi. $10.1080 / 14681810903265295$.

Olweus, D. (1993). Victimisation by peers: Antecedents and long-term outcomes. In K.H. Rubin and J.B. Asendorpf (eds.) Social withdrawal, inhibition and shyness in childhood (pp. 315-341), Erlbaum, Hillsdale, NJ.

Olweus, D. (1978). Aggression in the schools: Bullies and whipping boys. New York, NY: Wiley.

O’Moore, M., \& Kirkham, C. (2001). Self - esteem and its relationship to bullying behaviour. Aggressive Behavior: Official Journal of the International Society for Research on Aggression, 27(4), 269-283. Doi: 10.1002/ab.1010.

Persson, M., Svensson, M., Karlstads universitet, Fakulteten för ekonomi, kommunikation och IT, \& Avdelningen för nationalekonomi och statistik. (2013). The willingness to pay to reduce school bullying. Economics of Education Review, 35, 1-11. doi:10.1016/j.econedurev.2013.02.004.

Roach, G. (2014) A Helping Hand? A Study into an England-wide Peer Mentoring Program to Address Bullying Behavior, Mentoring \& Tutoring: Partnership in Learning, 22:3, 210-223, DOI: 10.1080/13611267.2014.926663.

Thornberg, R., Jungert, T., Utbildningsvetenskap, Pedagogik och didaktik, Linköpings universitet, Institutionen för beteendevetenskap och lärande, . . Psykologi. (2013). 
Bystander behavior in bullying situations: Basic moral sensitivity, moral disengagement and defender self-efficacy. Journal of Adolescence, 36(3), 475-483. doi:10.1016/j.adolescence.2013.02.003.

Turunen, T., \& Punamäki, R. (2016). Professionally led peer support group process after the school shooting in finland: Organization, group work, and recovery phases. OMEGAJournal of Death and Dying, 73(1), 42-69. doi:10.1177/0030222815575700.

Tzani-Pepelasi C., Ioannou M., Synnott J. and Ashton, S. A. (2018). Comparing Factors Related to School-bullying and Cyber-bullying. Journal of Crime Psychology Review. DOI: $10.1080 / 23744006.2018 .1474029$.

Virtanen, T. E., Lerkkanen, M., Poikkeus, A., \& Kuorelahti, M. (2014). Student behavioral engagement as a mediator between teacher, family, and peer support and school truancy. Learning and Individual Differences, 36, 201-206. doi:10.1016/j.lindif.2014.09.001.

Visser, M. J. (2004). Implementing peer support in schools: Using a theoretical framework in action research. Journal of Community \& Applied Social Psychology, 14(6), 436-454. doi:10.1002/casp. 788 .

Waters, S., Lester, L., \& Cross, D. (2014;2013;). How does support from peers compare with support from adults as students transition to secondary school? The Journal of Adolescent Health : Official Publication of the Society for Adolescent Medicine, 54(5), 543. doi:10.1016/j.jadohealth.2013.10.012.

White, I., Foody, M., \& Norman, J. O. H. (2019). Storytelling as a Liminal Space: Using a Narrative Based Participatory Approach to Tackle Cyberbullying Among Adolescents. In Narratives in Research and Interventions on Cyberbullying among Young People (pp. 133-146). Springer, Cham. Doi: 10.1007/978-3-030-04960-7_9.

Whybra, L., Warner, G., Bjornstad, G., Hobbs, T., Brook, L., Wrigley, Z., ... \& Eames, T. 
(2018). The effectiveness of Chance UK's mentoring programme in improving behavioural and emotional outcomes in primary school children with behavioural difficulties: study protocol for a randomised controlled trial. BMC psychology, 6(1), 9.

Williams, K., Chambers, M., Logan, S., \& Robinson, D. (1996). Association of common health symptoms with bullying in primary school children. British Medical Journal, 313(7048), 17-19. Retrieved from http://www.ncbi.nlm.nih.gov/pmc/articles/PMC2351438/.

Williford, A., \& Depaolis, K. J. (2016). predictors of cyberbullying intervention among elementary school staff: The moderating effect of staff status. Psychology in the Schools, 53(10), 1032-1044. doi:10.1002/pits.21973.

Williford, A., Boulton, A., Noland, B., Little, T. D., Kärnä, A., \& Salmivalli, C. (2012). Effects of the KiVa anti-bullying program on adolescents' depression, anxiety, and perception of peers. Journal of Abnormal Child Psychology, 40(2), 289-300. doi:10.1007/s10802-011-9551-1.

Yerger, W., \& Gehret, C. (2011). Understanding and dealing with bullying in schools. The Educational Forum, 75(4), 315-326. doi:10.1080/00131725.2011.602468. 